\title{
Response to Carter and Sánchez Delgado: questions of accuracy and intellectual integrity*
}

June 2020

Note on context. I am responding during the COVID-19 pandemic and international protests against racism. This response reflects an effort more compressed in time and scope than otherwise might be possible.

Transparency about my interactions with the authors. These interactions have differed from usual procedures when articles are submitted for publication. Through an email message, Eric Carter approached me about this article in December 2018. He asked if he could obtain my reaction to an earlier, Spanish-language draft. Because the article already was in the revise and resubmit stage for publication, he said he needed a rapid response from me, but he did not identify the journal. I sent Eric a detailed response. Later Eric revealed the identity of this journal, but he did not provide the revised article.

Transparency about my interactions with the editor. I have benefited from a long-term relationship with my highly esteemed colleague Marcos Cueto. Marcos did not request that I participate in this article's peer review. After Eric Carter identified the journal, I contacted Marcos, requested a copy of the accepted version, and expressed concerns about it. Marcos invited me to submit a response. The word limit for this response has required cuts of my longer and more comprehensive text and references, which are available on request (waitzkin@unm.edu).

Concerns about the article as expressed to the authors and editor. As I wrote to Marcos in May 2019: “... When Eric ... approached me, I felt completely open to acknowledging that I made an error... But having rechecked my sources, I have reached the same conclusions as earlier, actually even more so." The earlier, Spanish-language version of the article contained several factual inaccuracies, including an erroneous claim that I had stated Salvador Allende was Max Westenhöfer's student. After I communicated this error to Eric in January 2019, he and his co-author modified the article slightly ("A master-disciple type of relationship is logically implicit in this statement [by Waitzkin], while in works that cite Waitzkin it becomes a concrete teacher-student relationship") but did not allude to their own earlier error. My writings contained no implication of a "master-disciple type of relationship," and the authors' inference of that relationship in my work is not supported. Clearly, some others (including Wikipedia, which the authors do not mention) did attribute erroneously to my writings a

\footnotetext{
* [Editor's note] This letter responds to an article (http://dx.doi.org/10.1590/S0104-59702020000400011) published in this issue.
} 
characterization of Westenhöfer and Allende as teacher and student, but before accepting that erroneous attribution, the authors could have checked my original publications.

Concerns that I expressed to Eric on January 11, 2019, remain now [additional text that I added after that date appear in brackets]:

[Intellectual integrity] ... your article, by questioning the veracity of my research, raises a fundamental issue of intellectual and academic integrity. If you are correct, the publication of your article in its current form could create a major problem for me by claiming to show the inaccuracy of the connection I have drawn through my research linking Virchow, Westenhöfer, and Allende. If you are not correct, then the concerns about intellectual and academic integrity would apply to you and your colleague.

[Factual inaccuracy]. I don't think I have written or said that Allende was Westenhöfer's student. To make that claim would have been implausible... If you know a place where I've said that, I'd appreciate your please showing me where. In case I did say that, or if anybody else has characterized my work as saying that, ... I should try to correct the record... I did make statements similar to the following quotation from our article in the American Journal of Public Health during 2001: "For instance, a prominent German pathologist, Max Westenhöfer... influenced a generation of students, including Salvador Allende," .... I stand by the statement. To say that Westenhöfer influenced Allende is not to say that Allende was Westenhöfer's student.

[Westenhöfer's and Virchow's influence]. I reached the conclusion that Westenhöfer and his work influenced Allende from in-depth research on Latin American social medicine, using archival documents and interviews that I conducted under a Fulbright fellowship and other grants between 1994 and 1996. Among those interviews was one with María Angélica Illanes, who educated me for the first time about Westenhöfer as Virchow's student and an influential professor of pathology in Chile. However, multiple other interviewees also referred to Westenhöfer and his impact. Our two articles on Latin American social medicine that appeared during 2001 in The Lancet and the American Journal of Public Health originally comprised a 4-part series of articles, which contained considerably more depth and breadth.... So the reference to Illanes is only to her book, because referencing the interview would have required considerably more space, and the connection between Westenhöfer and Allende actually comprised a relatively minor component....

A close reading of the social epidemiology produced by Virchow, Westenhöfer, and Allende leads to a conclusion that they all were using an inherently social medicine model, and the resemblance in analytic techniques and interpretations is often astonishing. One of many examples involves their accounts of tuberculosis. All these works documented extensively what are now called the social determinants of morbidity and mortality in tuberculosis, including poverty, inequality, adverse housing, pollution, educational deficiencies, lack of organizing among workers, and other social conditions.

Although you and your colleague cite later and, in my and others' view, problematic writings of Westenhöfer on eugenics, you don't analyze the important five articles on Chile's social conditions affecting morbidity and mortality in tuberculosis and many other 
diseases, published in German. You refer to a later translation of this work into Spanish but do not consider these papers in depth... A biographical article about Westenhöfer by Germán Manríquez (1995), published in La Revista Médica de Chile, which you do not cite, clarifies that Westenhöfer's work on social conditions in population health was well known in Chile before Westenhöfer left Chile in 1911 under duress, and that the work led to opposition from conservative sectors in academic medicine and among politicians, as well as wide support for Westenhöfer among students, labor unions, and other progressive groups, who demonstrated in Westenhöfer's defense. [As Manríquez points out, and as the article by Sievers Wicke (1958) that you cite also points out, Westenhöfer's report (Westenhöfer, 1959), which emphasized the adverse impact of Chile's social conditions on health conditions, was scheduled for publication in the August 1911 issue of the Annals of the University of Chile but was censured and withdrawn from publication by the council of the faculty of medicine. Until its eventual publication in 1958, according to multiple of my informants, copies of the Spanish version of this report continued to circulate in Chile, including the periods when Allende studied pathology and later delivered a talk in 1951 at Westenhöfer's testimonial event, while Allende as an elected senator was pursuing the creation of the Chilean national health service. If you had read either the German or Spanish version of Westenhöfer's report, I see no way you honestly could have concluded, as you state: "Although he was a pupil of Virchow, Westenhöfer seems to have followed his line of research in pathological anatomy, and was not interested in the socio-medical or political thinking of his teacher."]

You do not cite or explore any work at all published by Virchow either in German or in translation. By not analyzing any original work on social medicine by either Virchow or Westenhöfer, or comparing their published work to Allende's, you seriously weaken your arguments.

You emphasize the lack of academic citations by Allende to Virchow and Westenhöfer, but the work published under Allende's authorship (actually written by a team under his direction) was intended as part of a political platform of a popular front government, not as an academic publication. Even if it were an academic publication, ... the unavailability of this work in Spanish [partly due to censorship] doubtless affected the lack of citation, even though the publications generated political opposition to Westenhöfer ... [and remained well known in Chile]... La realidad médico-social chilena, as well as many public presentations that reflected Allende's policy efforts as an activist, senator, and president, manifest the same approach to social medicine that Virchow and Westenhöfer had used before him.

[Historiographic approach]. By exaggerated emphases on Virchow, Westenhöfer, and Allende, you essentially are adopting a "great man" perspective in ... history. A more fruitful approach would involve situating the efforts of these three individuals within the broader social, economic, and political structures and processes that were occurring when they lived.

... finally, is refuting a connection between Westenhöfer and Allende important? In addition to Westenhöfer's orientation, many other individuals and social movements influenced Allende. In my work, I have explored only some of these influences that 
Allende acknowledged in social medicine, such as the labor movements led by Emilio Recabarren and others, the left-wing parties in Chile over a long historical trajectory, the so-called right wing of social medicine during its "golden age" (including the contributions of Eduardo Cruz-Coke and others whom you and your colleague do mention), and many others... [In multiple works that you cite, I have emphasized roots of Latin American social medicine that arose independently, without sources in Europe, and sometimes even emerging from ideas about health in indigenous cultures.]

Further on Westenhöfer's influence: While the article was in press, I recontacted one of my interviewees (an eminent scientist who has participated anonymously, due to safety concerns, in our group studying Latin American social medicine since the time of the coup and dictatorship in Chile) and shared the article with him. This trusted informant reconfirmed his earlier statements about Westenhöfer's long-term influence on Allende's generation and even the subsequent generation of people working in Chilean social medicine. Finally, he emphasized that Carter and Sánchez Delgado do not refer to interviews with living people who studied with Westenhöfer, his trainees, or their trainees, and who continued to talk about Westenhöfer's contributions to social medicine at the University of Chile (where my colleague was a student under a pathology trainee taught by Westenhöfer) and elsewhere.

Conclusion. The article by Carter and Sánchez Delgado suffers from factual inaccuracies; issues of intellectual integrity; incomplete referencing of writings by Virchow and by Westenhöfer; lack of input from people in Chile and elsewhere who were influenced by Virchow, Westenhöfer, and Allende; and a historiographical approach that overemphasizes the importance of "great men" rather than broader social, economic, and political structures and processes. Latin American social medicine deserves more skillful historical assessment than this article achieves.

\section{REFERENCES}

MANRÍQUEZ, Germán.

Profesor Max Westenhöfer (1871-1957) en Chile. Revista Médica de Chile, v.123, n.10, p.1313-1317.

Available at: <https://pubmed.ncbi.nlm.nih.gov/8733326>. Access on: 20 June 2020. 1995.

SIEVERS WICKE, Hugo K.

Max Westenhöfer (1871-1957). Anales de la Universidad de Chile, v.116, n.112, p.47-93. Available at: <https://revistas.uchile.cl/index.php/ANUC/article/view/10921/11177>. Access on: 20 June 2020. 1958.

WESTENHOEFFER, Max.

Informe sobre la actividad del Instituto de Anatomía Patológica de la Universidad de Chile en los años 1908-1909. Anales de la Universidad de Chile, v.117, n.114, p.95-135. Available at: <https://anales.uchile.cl/ index.php/ANUC/article/view/18802/19899>. Access on: 20 June 2020. 1959.

Howard Waitzkin ${ }^{i}$ 